Journal of Patient-Centered

Volume 5

Issue 1 -- Health Disparities and Inequities: Part

Article 5 II

$1-30-2018$

\title{
Needs Assessment for Creating a Patient-Centered, Community- Engaged Health Program for Homeless Pregnant Women
}

\author{
Tegan Ake \\ Sabina Diehr \\ Leslie Ruffalo \\ Emily Farias \\ Ashton Fitzgerald \\ Samuel D. Good \\ Lindsay B. Howard \\ Stefan P. Kostelyna \\ Linda N. Meurer
}

Follow this and additional works at: https://aah.org/jpcrr

Part of the Community Health and Preventive Medicine Commons, Health and Medical Administration Commons, Maternal and Child Health Commons, Medical Education Commons, and the Medical

Humanities Commons

\section{Recommended Citation}

Ake T, Diehr S, Ruffalo L, Farias E, Fitzgerald A, Good SD, Howard LB, Kostelyna SP, Meurer LN. Needs assessment for creating a patient-centered, community-engaged health program for homeless pregnant women. J Patient Cent Res Rev. 2018;5:36-44. doi: 10.17294/2330-0698.1591

Published quarterly by Midwest-based health system Advocate Aurora Health and indexed in PubMed Central, the Journal of Patient-Centered Research and Reviews (JPCRR) is an open access, peer-reviewed medical journal focused on disseminating scholarly works devoted to improving patient-centered care practices, health outcomes, and the patient experience. 


\title{
Needs Assessment for Creating a Patient-Centered, Community-Engaged Health Program for Homeless Pregnant Women
}

\author{
*Tegan Ake, M2, *Sabina Diehr, MD, Leslie Ruffalo, PhD, Emily Farias, M2, Ashton Fitzgerald, M2, \\ Samuel D. Good, M3, Lindsay B. Howard, M2, Stefan P. Kostelyna, M2, Linda N. Meurer, MD, MPH \\ Department of Family and Community Medicine, Medical College of Wisconsin, Milwaukee, WI
}

Purpose Women who experience homelessness during pregnancy have poorer birth outcomes than the general population. This exploratory research describes the needs assessment of homeless women currently living at a shelter in Milwaukee, Wisconsin, to identify unmet needs related to maternal and infant perinatal health as the first step in designing a mutually beneficial patient-centered service-learning program for medical students to address these needs.

Methods Two 1-hour focus groups were held at a shelter for women who are homeless and/or victims of domestic violence. A total of 13 women participated in each session; four medical students and a physician served as facilitators and scribes at each session. The facilitators alternated asking predetermined open- and close-ended questions, followed by discussion among participants. Questions elicited experiences during pregnancy, what went well, what women living in the shelter struggled with, and what support they wished for but did not have. Scribes captured the conversation through hand-written notes and used content analysis in order of frequency.

Results Thirteen themes were identified. The 5 most frequently identified themes were a need for pregnancy education, access/transportation, baby care, advocacy, and material necessities. Participating shelter residents and the medical students expressed interest in working with one another and forming a longterm partnership with the shelter.

Conclusions Results of this needs assessment will inform the creation of a new shelter-based medical education program that will meet homeless women's needs while preparing medical students for patient-centered, community-responsive care. (J Patient Cent Res Rev. 2018;5:36-44.)

Keywords homeless persons; pregnancy; infant mortality; service-learning; health status disparities

\section{INTRODUCTION \\ Background}

Infant mortality remains an important marker of a community's well-being. ${ }^{1}$ Factors contributing to infant mortality are complex and tied to many social

*These authors contributed equally to this work.

Correspondence: Sabina Diehr, MD, Medical College of Wisconsin, 8701 Watertown Plank Road, Milwaukee, WI, 53226, T: +1-414-955-8876,

Email: sdiehr@mcw.edu determinants of health. ${ }^{2}$ Women who experience homelessness during pregnancy have poorer than average birth outcomes and are at higher risk for suffering the death of a child. Whether chronic or temporary, the stress of homelessness, and the events contributing to homelessness, have a significant impact on birth outcomes. Studies have shown that women who self-reported as being homeless during their pregnancy were more likely to have low-birth-weight infants and premature infants. ${ }^{3-5}$ Infants born weighing less than $2500 \mathrm{~g}$, and infants born at less than 37 weeks gestational age, suffer some of the highest rates of neonatal and infant death in the United States. ${ }^{6,7}$ 
The factors contributing to poorer birth outcomes and increased IMR in homeless women are complex and vary based on the community. Homeless women experience higher rates of domestic violence and other traumatic events and report more chronic stress related to financial and housing instability, all of which have been associated with premature births and lower birth weight. ${ }^{3,8-10}$ African American women constitute a disproportionately high percentage of the homeless population, and chronic stress related to racism also has been associated with lower birth weights and more premature births. ${ }^{2,11,12}$

Homeless women are more prone to have behavioral and health risk factors that are known to lead to worse birth outcomes. For example, homeless women have higher rates of cigarette, alcohol, and illicit drug use during pregnancy, and higher risk of being either underweight or overweight. . $^{3,8-10,12}$ These personal health risk factors can lead to infants with lower birth weights and more maternal and infant complications during birth. Homeless women also tend to have subsequent pregnancies at shorter intervals. Pregnancies spaced less than 18 months apart are associated with increased rates of prematurity. ${ }^{2}$

Despite the available information on the impact of homelessness on pregnancy and the associated risk factors for infant mortality, there is little information on current programs that specifically support women who are both homeless and pregnant. Since the needs of each community and the barriers encountered by woman in a given community can vary, an effective program must therefore address multiple social and personal risk factors while being responsive to local needs.

\section{Setting}

Milwaukee is considered the most segregated city in the United States, and it is one of the top 10 most impoverished big cities in the country. ${ }^{2}$ While several successful campaigns have been launched to improve IMR in Milwaukee, the local IMR remained at 9.1 (deaths per 1000 live births) in 2016, ${ }^{13}$ compared to 2015 national and state averages of 5.8. ${ }^{14}$ These campaigns have included the city's "Safe Sleep" campaign (http://city.milwaukee.gov/health/SafeSleep-Campaign) to discourage co-sleeping and thereby decrease IMR caused by accidental asphyxiation, and the University of Wisconsin School of Medicine and Public Health's "Lifecourse Initiative for Healthy Families" (https://lihf.wisc.edu), a collaboration of community organizations aimed at improving IMR and health in Wisconsin's African American population. Poverty and unemployment are markedly higher in this minority population, and certain health outcomes, such as IMR, also tend to be worse. ${ }^{2}$ The African American population of Wisconsin has had a significantly higher IMR than any other race in the state; in 2016 African American women were 2.7 times more likely to experience an infant death than non-Hispanic Caucasian women. ${ }^{13}$ Even as the IMR improves statewide, more efforts are needed to help the most vulnerable populations in Milwaukee.

Since 2011, the Homeless Outreach in Medical Education (HOME) Project, a service-learning educational program at the Medical College of Wisconsin (Milwaukee, WI), has partnered with the Milwaukee Women's Center to provide health education on community-identified health topics. The Milwaukee Women's Center provides housing for homeless women and victims of domestic violence. Shelter residents work directly with caseworkers who help find employment and permanent housing opportunities and who provide counseling and addiction services. Through HOME, medical students, under faculty mentor guidance, present educational modules on smoking cessation, sexually transmitted infection prevention, and reproductive health at the shelter twice a month. Although the shelter houses approximately 3-4 pregnant women on any given day, currently there is no formal program in place to provide residents with prenatal and perinatal assistance and education. Shelter administrators and, anecdotally, shelter residents have professed a need for guidance, education, and continued support for pregnant women.

\section{Project Aim}

One proposed extension of HOME, the Health Advocacy in Pregnancy \& Infancy (HAPI) program, was conceived as service-learning outreach intended to benefit homeless pregnant women and their babies while meeting the educational needs of medical students enrolled in the college's Urban and Community Health Pathway curriculum. ${ }^{15}$ Through HAPI, students will apply principles of community engagement — directly 
interacting with community members who might potentially benefit to obtain input and ideas for the structure and goals of the program - to design a series of sustainable interventions that are most responsive to the needs of that community. By improving pregnancy and childcare education, and encouraging healthy behaviors during pregnancy, HAPI's goal is to decrease infant mortality in a high-risk population.

Conducted as a mentored, medical student servicelearning experience, this exploratory study describes the first step in creation of HAPI: a formal assessment to identify unmet needs related to maternal and infant health of the women currently residing at a homeless/emergency shelter. Results may inform the development of patient-centered, community-engaged programming for homeless mothers and their babies.

\section{METHODS}

The Medical College of Wisconsin institutional review board granted expedited approval (PRO00028835) in March 2017 for conducting two focus groups at the Milwaukee Women's Center.

\section{Participant Recruitment}

All healthy, adult women currently residing at the Milwaukee Women's Center were eligible to participate. Participation was limited to current shelter residents. Flyers inviting shelter residents to attend one of two focus groups were posted in the common living areas. Shelter staff again announced the time and location of each focus group and invited residents to attend. In consideration of the center's high turnover rate, the focus groups were held 2 weeks apart to capture different shelter residents and different points of view. To boost attendance, each focus group was held after the shelter's evening curfew. Regardless of level of participation, all attendees of the focus groups received a gift lunch bag.

\section{Data Collection}

Both focus groups were held in the common meeting room at the shelter and lasted for 1 hour each. Each focus group consisted of 13 shelter residents and 5 facilitators/scribes from Medical College of Wisconsin, including 4 medical students and a physician. Prior to the focus groups, students were trained by research staff experienced in community outreach, qualitative data analysis, the conduction of focus groups, and asking open-ended questions. At the beginning of each focus group, the facilitator(s) reminded participants that their participation was voluntary, that no personal information would be collected, and that only handwritten notes would be recorded.

Prior to initiating the focus groups, the facilitators decided on predetermined open- and close-ended questions (Table 1), followed by discussion among the shelter residents. The close-ended questions served as a launching point for the residents to expand on ideas

Table 1. Focus Group Protocol

\footnotetext{
Open-ended questions

1. What are some of the biggest challenges women face during pregnancy / after the birth of a child?

2. What were some of the greatest strengths women have during pregnancy / after the birth of a child?

3. What do most women wish they had in terms of support during pregnancy / after the birth of a child?

4. How important is the support of other women during pregnancy / after the birth of a child?

\section{Closed-ended questions}

In your opinion, how important [not at all / somewhat / very] is/are:

a. Informal classes on health/baby topics?

b. Help setting up doctors' appointments, prenatal visits?

c. Transportation to doctors' appointments, prenatal visits (bus passes, rides, other)?

d. Rewards for going to prenatal visits (nursery items, grocery gift cards, other)?

e. Nursery items (diapers, baby clothes, car seat, formula, etc.)?

f. Help arranging for child care?

g. Cooking sessions for making your own baby food?

h. Advice on grocery shopping for healthy foods?

i. Being part of a supportive community (regular get-togethers, outings, other)?

j. Website with resources for pregnant women and new mothers?
} 
presented by the group. For example, residents were asked to comment on the usefulness of students to act as medical advocates as a potential intervention. Unprompted, it is unlikely that residents would have requested student liaisons as medical advocates. Participating residents were primarily asked openended questions, such as describing positive or negative experiences during pregnancy or what support they wished for but did not have.

During each session, the facilitators took hand-written notes for later comparison and analysis. Facilitators emphasized open-ended questions with clarifying questions as needed. The conversation was facilitated, but if the conversation naturally veered toward a possible intervention, specific follow-up questions were asked. Immediately after each focus group, the facilitators met briefly and discussed the major emerging themes as well as the effectiveness of the facilitation methods. The hand-written notes were transcribed verbatim using Microsoft Word to serve as the source documents for analysis. Comparison of the collected notes was utilized to capture reliability and assess for discrepancies.

In 2016 this shelter recorded 66\% African American, 20\% multiracial, 14\% Caucasian, and 6\% Hispanic/ Latino residents. ${ }^{16}$ No specific personal or demographic information was collected from the focus group participants due to the sensitive nature of working with the homeless population and women who have experienced domestic violence. This is also why handwritten notes were taken rather than audio or video recordings. Over $90 \%$ of participants volunteered that they had been pregnant before, but none of the participants shared whether they were currently pregnant. Due to scheduling conflicts for both the students and the shelter, additional focus groups were not performed. No new themes emerged in the second focus group.

After the focus groups had been completed and the data analyzed, additional confirmatory input was sought by interviewing key shelter staff. Also, anonymous surveys with identical questions to those asked in the focus groups were placed in the shelter lobby during the 2-week time between focus groups. Out of 100 surveys, only 3 were returned. The 3 surveys obtained mirrored the responses in the focus groups and did not add additional information. Thus, only the methods used for the focus groups will be described.

\section{Qualitative Data Analysis}

The project team analyzed the focus group data using a hybrid approach of directed and summative content analysis. ${ }^{17}$ Focus group questions were written based on literature surrounding commonly expressed needs within the homeless population and previous discussions with the staff and residents of the shelter. While the focus group questions formed the basis of the initial codes of the qualitative data analysis, the final codes were decided on after the focus groups were conducted. The final codes were intended to provide a framework for categorizing the themes that emerged during the focus groups. Source documents for the analysis included the 11 transcripts generated from the facilitators' handwritten notes. Transcripts were analyzed by highlighting pieces of text and assigning one of the predetermined codes to each piece of additional information. The project team used summative content analysis techniques to determine which codes were used most frequently, thereby identifying the most dominant themes from the focus groups. ${ }^{18}$

The first step in the coding process was for each of the 8 coders to independently code their transcripts based on the initial code list described earlier. All coders then met face-to-face to discuss any areas of confusion or potential bias in the coding and to update the code list. Lastly, the coding team split into 2 groups of 4 to re-code all transcripts and reach consensus that the coding list was appropriate and captured the true meaning of the text. Multiple coding was allowed at the discretion of each coder, but specific statements that were recorded by multiple scribes were not double-coded (ie, one person stating that "diabetes was a struggle" during her pregnancy was only coded once). Totals were obtained by pooling data from all coders and from both focus groups. The categories were ranked in order of frequency.

Since most of the coders had also been facilitators/ scribes during the focus groups, they were able to clarify the intended meaning in their own notes as needed. Most discrepancies in the coding process were due to erroneous double-coding, but there was overall 
high intercoder consistency. The numeric results obtained by the coders were approved by the team of facilitators as being representative of what the women conveyed during the focus groups.

\section{RESULTS}

\section{Unmet Needs Identified}

We identified 13 themes from the focus groups (Table 2). Focus group participants most frequently spoke about the lack of, or appreciation for, pregnancy education both during and after pregnancy, and requested short and focused modules concerning specific topics. The women believed that having better access to such educational modules would have helped during prior pregnancies and childbirths as well as being beneficial for current health and wellness. Stated needs included what to expect during pregnancy and childbirth, and health and wellness after the birth of their child. Shelter residents thought that pregnancy education would be particularly valuable for new mothers. Representative quotes are: "I could never afford Lamaze classes, but I wanted to stay informed;" "I wish I had a midwife to explain things to me;" and "I wish somebody would have told me what could happen after [birth] — what not to do." The Internet was identified as a valuable resource for obtaining health information, but the participants requested information about trustworthy websites and phone applications to assist them with pregnancy-related questions.

Access to physician appointments and transportation presented various levels of difficulty. Some women found that community resources, such as free bus passes, made it easy to get to appointments, whereas others found bus rides too difficult and had to apply for taxi vouchers instead. Lack of childcare was a barrier to health care, and the need of bringing younger children along to doctors' appointments was particularly difficult when taking the bus.

The need for more education and understanding of how to take care of babies was the third most frequent topic discussed during the focus groups. Shelter residents specifically requested information on how to handle a baby with a fever, a colicky baby, and how to make their own baby food. Education on safe sleep also was requested. Representative quotes are: "I never know when I should call the ambulance" and "I was so scared when my baby cried." Residents also endorsed the idea of creating a peer support group in which mothers could share information related to health and pregnancy. One woman stated that she did not have any friends until she came to the center but has found friendship and support with the other women in the shelter. "I did not know I can make my own baby food. Can you show me how?" was echoed by many similar requests for "words of wisdom."

The women in the focus groups also requested assistance in making doctor appointments for their babies, noting how difficult it can be to find a physician with whom they feel comfortable. Many women "felt like a number." Several women had trouble comprehending or reading information at their doctor appointments, either because of a language barrier or functional illiteracy. One woman said: "I wished someone would've been there to help answer questions and explain things." The women were open to the idea of working with medical students. A representative quote is: "It would be awesome to have someone in the field be on my side."

During the focus groups, the women expressed a desire to eat well, but common barriers cited included a lack of access to healthy foods and a lack of education about cooking, nutrition, and diet. "I did not know how to deal with my cravings when I was pregnant" and "I am a diabetic and have high blood pressure but have no idea what to eat that's good for me and baby," were typical sentiments offered.

Staff interview data yielded comparable results and reinforced the themes mentioned by residents. Regarding barriers for pregnant women at the shelter, it was noted that women often miss doctor appointments due to lack of transportation and childcare. Caseworkers can sometimes take the women directly, but this is only available while the women reside at the shelter, which is 30 days on average. Many women use their WIC benefits at convenient locations such as corner stores, where unhealthy and more expensive substitutions are often made. Regarding medical advocacy, it was noted that some of the women would greatly appreciate a medical student advocate, but that others would be hesitant to have a stranger in a position of authority "in their business." Caseworkers currently 
Table 2. Major Categories and Concepts From Focus Groups for Improving Pre- and Postnatal Experience for Homeless Pregnant Women

\begin{tabular}{|c|c|c|}
\hline Rank* $^{*}$ & Category & Concepts \\
\hline 1 & Pregnancy education & $\begin{array}{l}\text { - Explain normal pregnancy } \\
\text { - Explain normal delivery } \\
\text { - Managing hypertension, diabetes mellitus, cravings, etc. } \\
\text { - Postpartum health, including postpartum depression } \\
\text { - Lamaze classes }\end{array}$ \\
\hline 2 & Access/transportation & $\begin{array}{l}\text { - Additional transportation options } \\
\text { - Childcare during times of prenatal visit } \\
\text { - Help scheduling doctor appointments }\end{array}$ \\
\hline 3 & Baby care & $\begin{array}{l}\text { - Advice on baby illnesses, fevers, soothing, etc. } \\
\text { - Advice on baby hygiene-products (make it yourself) } \\
\text { - How to make baby food } \\
\text { - Breastfeeding classes } \\
\text { - Finding a good baby doctor }\end{array}$ \\
\hline 4 & Advocacy & $\begin{array}{l}\text { - Advocate during prenatal visit (ask questions, explain) } \\
\text { - Advocate during labor and delivery (ask questions, explain) } \\
\text { - Someone who takes you seriously } \\
\text { - Medical students to accompany during prenatal visits } \\
\text { - Medical students to accompany during labor and delivery }\end{array}$ \\
\hline 5 & Material necessities & $\begin{array}{l}\text { - Need for maternity clothes } \\
\text { - Needs for baby clothes } \\
\text { - Need for diapers, car seats, etc. }\end{array}$ \\
\hline 6 & Network & $\begin{array}{l}\text { - Having someone to ask for advice } \\
\text { - Having someone to relate to with similar experience } \\
\text { - Importance of a peer/parenting group } \\
\text { - Need of a forum to share ideas }\end{array}$ \\
\hline 7 & Healthy diet & $\begin{array}{l}\text { - Importance of healthy eating during pregnancy } \\
\text { - What are healthy snacks } \\
\text { - What foods to buy } \\
\text { - Where to buy food cheaply } \\
\text { - How to prepare healthy foods }\end{array}$ \\
\hline 8 & Communication & $\begin{array}{l}\text { - Information in native language } \\
\text { - Handouts in Spanish } \\
\text { - Translator during prenatal visits } \\
\text { - Help read/understand information for poor readers/illiterates }\end{array}$ \\
\hline 9 & Financial need & $\begin{array}{l}\text { - Need to find a job } \\
\text { - Need to find a better paying job } \\
\text { - Difficulty maintaining a job while pregnant }\end{array}$ \\
\hline 10 & Personal relationships & $\begin{array}{l}\text { - How to maintain good relationship with partner } \\
\text { - How to find a supportive partner } \\
\text { - How to maintain good relationships with family / friends }\end{array}$ \\
\hline 11 & Stress management & $\begin{array}{l}\text { - Coping strategies for stress, such as partner in jail, etc. } \\
\text { - Eliminate sources of stress }\end{array}$ \\
\hline 12 & Housing & - Need to find permanent housing \\
\hline 13 & Internet & $\begin{array}{l}\text { - Access to the Internet } \\
\text { - Education on how to use the Internet } \\
\text { - Sharing of useful phone apps }\end{array}$ \\
\hline
\end{tabular}

${ }^{*}$ Codes are ranked in order of most to least frequent; data pooled from both focus groups. 
have a parenting group but would appreciate help from students. Overall, a need for more interventions for the pregnant women who reside at the shelter was identified and there was excitement about the potential implementation of a long-term HAPI program.

\section{Reflections on Process}

Debriefings among the student and faculty facilitators/ scribes at the end of each focus group affirmed that the formatting of open-ended questions followed by a few specific questions worked well to unveil shared areas of need as well as focused needs applicable to several women. Holding the focus group sessions at the shelter after curfew helped ensure good participation and representation. Arranging the group in a large circle ensured relatively balanced participation. Many of the participating women brought their infants. Although this was not anticipated, the group was very welcoming, disruptions by the children were minimal, and their presence underscored the importance and relevance of the discussion.

\section{DISCUSSION}

The results of the focus groups were well aligned with previous findings regarding commonly expressed barriers and needs within the homeless population. Previous studies using qualitative research design identified several of the same barriers to perinatal health care mentioned by the women in the focus groups, including access and transportation difficulties, a need for material and financial assistance, and a feeling of being stigmatized at doctors' visits. ${ }^{19,20}$ Indeed, risk factors are confounded by a relative lack of access to health care recommended for all pregnant women. Homeless women are less likely to attend prenatal and well-child appointments at the recommended intervals. ${ }^{5}$ Bloom et al surveyed homeless women who were pregnant or had recently given birth and found that barriers to attending doctor appointments included lack of transportation, inability to schedule doctor visits within a reasonable timeframe, lack of childcare, and lack of insurance or knowledge how to obtain insurance. The women also expressed that perceived negative judgment from office staff deterred them from returning for their next appointment. ${ }^{19}$

The women in our focus groups expressed a desire for more education on health and wellness during and after pregnancy. This need for successful health promotion for the homeless also has been described in previous research. ${ }^{21}$ Adequate nutrition can be difficult for lowincome mothers due to limited access and knowledge about healthy options. ${ }^{3,5}$ Homeless women are less likely to eat balanced meals, take multivitamins, or breastfeed, all of which can lead to health complications for mothers and infants. ${ }^{5}$ Therefore, providing education on healthy and affordable meals, the importance of prenatal vitamins, and the value of breastfeeding is strongly supported.

Shelter residents requested increased social support during and after pregnancy from family, friends, and mentors, which has been a common theme in women who experience homelessness. ${ }^{22}$ Women who experience homelessness are less likely to have a stable social network that can assist them with transportation, temporary housing, childcare, and emotional support. ${ }^{3,5,9,10,22}$ This can make it difficult to navigate temporary economic hardships and the emotional toll effected by chronic stress.

Our results both reinforce previous findings and extend them to the specific population of the residents at the Milwaukee Women's Center. Additionally, we found a previously undocumented desire among the women for advocacy from medical students at physician appointments and more digital resources such as phone applications and reliable websites. Although the specific concerns expressed by the women during this needs assessment are common to many expectant and new mothers, the unique barriers, such as access to health care, transportation, or obtaining accurate information, are formidable for the homeless. ${ }^{3,5,8,10,19}$ The chronic poverty of the homeless only magnifies the challenges faced in navigating pregnancy and infant care. ${ }^{8,10}$ Homeless mothers not only must raise children while struggling with the previously mentioned barriers, but both mothers and children are at greater risk of experiencing ill health during and after pregnancy. $3,8-10,19$

\section{Limitations}

Small sample size and single-site setting may limit this study's generalizability. Since women's shelter populations are variable and turnover is rapid, we may have captured a nonrepresentative sample. However, 
findings were consistent with Milwaukee Women's Center staff expectations, and our longstanding relationship with this shelter and our communityengaged approach will allow ongoing adjustments as programs are implemented. Also, thematic saturation may have not been achieved. Although no new themes were identified in the second focus group, additional focus groups may have been informative. Other limitations include using students who, despite training, had little experience in conducting focus groups. On the other hand, this also served as a learning experience as students built effective communication and interviewing skills. Having the medical students introduce themselves as "students" and "eager to learn from the participants" eased tensions early and may have fostered open conversation. Asking targeted questions may be inherently "leading" but also enabled the research team to receive feedback on specific intervention options.

\section{Future Application}

This needs assessment for designing a communityengaged service-learning program aimed to 1) query representatives of the community in order to guide the types of services and educational programs offered by HAPI to future shelter residents, and 2) build trusting relationships among the students, staff, and residents as a key principle of community engagement. ${ }^{23}$ We aim to leverage the results of this needs assessment with the educational needs and capacity of the medical students and available resources of our institution and partners.

In continued community partnership with the residents and the staff of the shelter and other community partners, HAPI will help support women who find themselves homeless before and/or after the birth of a child. Planned interventions include facilitation of regular prenatal care, educational modules on pregnancy and infant care, nutrition and cooking classes, facilitation of a local peer group, and matching of medical students with shelter residents requesting health advocacy. By implementing HAPI, we hope to improve the birth outcomes of the pregnant shelter residents. Concurrently, medical students will gain valuable experiences with patient-centered care, advocacy for the homeless, and working with community organizations and resources. Medical students will learn about health promotion program design and evaluation, foster sustainability as they train successive cohorts of students, and participate in fundraising efforts to support ongoing program implementation and meaningful outcomes measurement.

\section{CONCLUSIONS}

The women who participated in this needs assessment for the creation of a new shelter-based health advocacy program valued education about pregnancy and how to best care for their children, above all else. Transportation, access to medical care, healthy diet, health advocacy, and a network of peers also were identified as needs affecting their ability to maintain good health for themselves and their children. Milwaukee Women's Center staff, the women living at the shelter, and the medical students and faculty will incorporate this assessment into the design of the Health Advocacy in Pregnancy \& Infancy education program, which aims to be a mutually beneficial, patient-centered, community-engaged initiative.

\section{Patient-Friendly Recap}

- Being homeless and pregnant increases a woman's risk of having a baby that is unhealthy or dies.

- To assess this population's needs, medical students asked women living in a shelter about what could make their pregnancies healthier.

- Shelter residents most highly valued education about pregnancy and caring for their baby as well as help understanding what happens during doctor visits.

- Identification of unmet needs will inform the design of a medical student program aimed at improving health outcomes for homeless pregnant women.

\section{Acknowledgments}

The authors are grateful for the collaboration and support of all the residents and staff at the Milwaukee Women's Center, with a special thank you to Madelene Amos.

\section{Author Contributions}

Study design: Diehr, Ruffalo, Meurer. Data acquisition or analysis: Ake, Diehr, Ruffalo, Farias, Fitzgerald, Good, Howard, Kostelyna. Manuscript drafting: Ake, Diehr. Critical revision: Ruffalo, Meurer, Farias, Fitzgerald, Good, Howard, Kostelyna. 


\section{Conflicts of Interest}

None.

\section{Funding Sources}

The authors are grateful for the financial support from the Medical College of Wisconsin's 2016 Community of Innovators Award. We also appreciate the financial support of the Wisconsin Medical Society Foundation's 2017 Summer Fellowship funding.

\section{References}

1. Reidpath DD, Allotey P. Infant mortality rate as an indicator of population health. $J$ Epidemiol Community Health. 2003;57:344-6. CrossRef

2. Ngui E, Michalski K, LeCounte E, Mohr A. 2017 City of Milwaukee Fetal Infant Mortality Review (FIMR) Report. Milwaukee, WI: Milwaukee Health Department, 2017.

3. Cutts DB, Coleman S, Black MM, et al. Homelessness during pregnancy: a unique, time-dependent risk factor of birth outcomes. Matern Child Health J. 2015;19:1276-83. CrossRef

4. Little M, Shah R, Vermeulen MJ, Gorman A, Dzendoletas D, Ray JG. Adverse perinatal outcomes associated with homelessness and substance use in pregnancy. CMAJ. 2005;173:615-8. $\underline{\text { CrossRef }}$

5. Richards R, Merril, RM, Baksh L. Health behaviors and infant health outcomes in homeless pregnant women in the United States. Pediatrics. 2011;128:438-46. CrossRef

6. Callaghan WM, MacDorman MF, Rasmussen SA, Qin C, Lackritz EM. The contribution of preterm birth to infant mortality rates in the United States. Pediatrics. 2006;118:1566-73. CrossRef

7. McCormick MC. The contribution of low birth weight to infant mortality and childhood morbidity. $N$ Engl $J$ Med. 1985;312:82-90. CrossRef

8. Merrill RM, Richards R, Sloan A. Prenatal maternal stress and physical abuse among homeless women and infant health outcomes in the United States. Epidemiol Res Int. 2011;(2011):467265. CrossRef

9. Weinreb L, Browne A, Berson JD. Services for homeless pregnant women: lessons from the field. Am J Orthopsychiatry. 1995;65:492-501. CrossRef

10. Bassuk EL, Weinreb L. Homeless pregnant women: two generations at risk. Am J Orthopsychiatry. 1993;63:348-57. CrossRef

11. Lu MC, Kotelchuck M, Hogan V, Jones L, Wright K, Halfon N. Closing the black-white gap in birth outcomes: a lifecourse approach. Ethn Dis. 2010;20(1 Suppl 2):S62-76.

12. Richards R, Merrill RM, Baksh L, McGarry J. Maternal health behaviors and infant health outcomes among homeless mothers: U.S. Special Supplemental Nutrition Program for Women, Infants, and Children (WIC) 2000-2007. Prev Med. 2011;51:87-94. CrossRef
13. Milwaukee Health Department. City of Milwaukee 2015 infant mortality review (IMR): data brief. [Epub 2016 Jun 14.] http:// city.milwaukee.gov/ImageLibrary/Groups/healthAuthors/ MCH/PDFs/InfantMortality/2015IMRDataBrief20160614ReleasedVersion.pdf. Accessed July 14, 2017.

14. Centers for Disease Control and Prevention. Infant mortality rates by state, 2016. https://www.cdc.gov/nchs/pressroom/ sosmap/infant_mortality_rates/infant_mortality.htm. Accessed July 14, 2017.

15. Meurer LN, Young SA, Meurer JR, Johnson SL, Gilbert IA, Diehr S; Urban and Community Health Pathway Planning Council. The urban and community health pathway: preparing socially responsive physicians through community-engaged learning. Am J Prev Med. 2011;41(4 Suppl 3):S228-36. CrossRef

16. Community Advocates. Milwaukee Women's Center. http:// communityadvocates.net/women/. Accessed December 1, 2017.

17. Creswell JW. Qualitative Inquiry and Research Design: Choosing Among Five Traditions. Thousand Oaks, CA: Sage Publications, 1998.

18. Hsieh HF, Shannon SE. Three approaches to qualitative content analysis. Qual Health Res. 2005;15:1277-88. CrossRef

19. Bloom KC, Bednarzyk MS, Devitt DL, Renault RA, Teaman V, Van Loock DM. Barriers to prenatal care for homeless pregnant women. J Obstet Gynecol Neonatal Nurs. 2004;33:428-35. CrossRef

20. Gelberg L, Browner CH, Lejano E, Arangua L. Access to women's health care: a qualitative study of barriers perceived by homeless women. Women Health. 2004;40:87-100. CrossRef

21. Power R, French F, Connelly J, et al. Health, health promotion, and homelessness. BMJ. 1999;318(7183):590-2. CrossRef

22. Beal AC, Redlener I. Enhancing perinatal outcome in homeless women: the challenge of providing comprehensive health care. Semin Perinatol. 1995;19:307-13. CrossRef

23. CTSA Community Engagement Key Function Committee Task Force on the Principles of Community Engagement. Principles of Community Engagement, Second Edition. Atlanta, GA: Centers for Disease Control and Prevention, 2011 (June). https://www.atsdr.cdc.gov/communityengagement/ pdf/PCE_Report_508_FINAL.pdf. Accessed October 11, 2017.

(C) 2018 Aurora Health Care, Inc. 